\title{
Produção e Exportação de Algodão: Efeitos de Choques de Oferta e de Demanda*
}

\author{
Lucilio Rogerio Aparecido Alves ${ }^{\dagger}$, Geraldo Sant'Ana de Camargo \\ Barros $^{\ddagger}$, Mirian Rumenos Piedade Bacchi ${ }^{\S}$
}

\author{
Conteúdo: 1. Introdução; 2. Revisão Bibliográfica; 3. Modelo Econômico; 4. Procedimentos \\ Metodológicos; 5. Resultados e Discussão; 6. Considerações Finais. \\ Palavras-chave: Algodão; Reestruturação; Agronegócio; VAR; Choques de Oferta; Demanda. \\ Códigos JEL: $\quad$ C32; E32; 013; 033; 041; 047.
}

O objetivo principal deste trabalho é examinar o padrão de crescimento da produção de algodão no Brasil desde os anos 1960 até os dias atuais, período em que se materializa a expansão da cultura para novas regiões do país, num novo sistema produtivo. Desenvolve-se um modelo econômico para aferir o crescimento do setor em termos de choques de oferta e de demanda. Os resultados apontaram que a produtividade da lavoura explica aproximadamente $30 \%$ do crescimento da produção e quase um quarto da evolução da exportação de algodão do Brasil. Outros 15\% do aumento da produção podem ser atribuídos à evolução do preço. Os resultados sugerem que, configurado um cenário de rentabilidade, o setor tende a ajustar a área e a produção durante um período de uma década ou mais, num processo auto-regressivo característico.

This paper is intended to analyze the growth pattern of the Brazilian cotton production after 1960. During this period the cotton crop expanded to new regions based on a new production system. An economic model is developed to

\footnotetext{
*O presente artigo é baseado na tese de doutorado do primeiro autor. Os autores agradecem a contribuição do(s) parecerista(s). Possíveis erros remanescentes são de inteira responsabilidade dos autores.

†Professor Doutor do Departamento de Economia, Administração e Sociologia - DEAS, da Universidade de São Paulo, Escola Superior de Agricultura "Luiz de Queiroz" (ESALQ/USP). Pesquisador do Centro de Estudos Avançados em Economia Aplicada - CEPEA/ESALQ/USP. Av. Pádua Dias, 11 - Caixa Postal 132 - 13400-970 - Piracicaba, SP - Brasil. Tel: 19-3429-8847. E-mail: lualves@esalq.usp.br

${ }^{\ddagger}$ Professor Titular da ESALQ/USP, Departamento de Economia, Administração e Sociologia - DEAS. Coordenador Científico do CEPEA/ESALQ/USP. Av. Pádua Dias, 11 - Caixa Postal 132 - 13400-970 - Piracicaba, SP - Brasil. Tel: 19-3429-8802. E-mail: gscbarrodesalq.usp.br

$\S$ Professora Associada da ESALQ/USP, Departamento de Economia, Administração e Sociologia - DEAS. Vice-Coordenadora Científica do CEPEA/ESALQ/USP. Av. Pádua Dias, 11 - Caixa Postal 132 - 13400-970 - Piracicaba, SP - Brasil. Tel: 19-3429-8802. E-mail: mrpbaccheesalq.usp.br
} 
measure the contributions of supply and demand shocks to the growth in cotton production. Thirty percent of that growth was attributed to productivity gains and $15 \%$ is related to the evolution of prices. Twenty five percent of the exports growth is attributed to productivity as well. The results indicate that once established an economic scenario - land area and production adjust to it according to an auto-regressive process over a decade or more.

\section{INTRODUÇÃO}

O objetivo principal deste artigo é examinar o padrão de crescimento da produção de algodão no Brasil entre os anos 1960 - quando se inicia a política de modernização da agricultura (Barros et alii (1977), Barros (1979), Szmrecsányi (1990), Baer (1996), Coelho (2001), Teixeira (2005)) - até os dias atuais, período em que se materializa a expansão da cultura para novas regiões do país, num novo sistema produtivo.

Desde meados dos anos 1970 os preços do algodão vêm caindo no Brasil e, mesmo assim, após a reestruturação dos anos 1990, a produção se expande de forma marcante. Neste trabalho argumenta-se que tal perfomance decorreu de uma conjugação de fatores de ordem tecnológica (do lado da oferta) e mercadológica (do lado da demanda tanto interna como externa). No primeiro caso, admite-se que capacidade empresarial e empreendedora dos produtores brasileiros, aliada às novas tecnologias geradas no Brasil e no exterior, foi essencial para que a produção de algodão e derivados alcançasse o elevado padrão de produtividade e eficiência dos dias de hoje. No segundo, reconhece-se a relevância das mudanças no consumo devido a desenvolvimento de substitutos bem como o papel-chave do mercado externo na formação de preços do algodão no Brasil.

A pergunta que se propõe é: o desenvolvimento da cotonicultura brasileira atribui-se predominantemente aos estímulos de demanda (interna e externa) ou a mudanças do lado da oferta através de avanços tecnológicos e gerenciais que resultaram em maior eficiência e produtividade?

Em geral, uma expansão da produção sem avanço tecnológico não tem como se dar sem a necessária expansão - via demanda - do mercado consumidor, sob pena de frustrar-se devido a queda de preços. Havendo apenas crescimento de demanda haverá, simultaneamente à expansão da produção, aumentos de preços decorrentes da necessidade de (a) afastar-se a produção dos centros consumidores ou de portos de exportação e/ou (b) substituir outras atividades por aquela em expansão a custos de oportunidade crescentes. Assim, o crescimento da produtividade é condição necessária para o crescimento da produção a preços constantes ou decrescentes.

Porém, o crescimento fundado no avanço tecnológico não se viabiliza de forma sustentada sem expansão do mercado. Na falta desta, resulta o que autores têm-se referido como armadilha do treadmill (Cochrane, 1958) ou de modernização auto-controlada (Paiva, 1968). A queda de preços mais cedo ou mais tarde contém a difusão das novas tecnologias, estancando o crescimento. A expansão da demanda (interna ou externa) simultaneamente ao avanço tecnológico é condição necessária para que se evite acentuada queda de preço, que inviabilize o uso da nova tecnologia, estancando os benefícios iniciais aos consumidores.

O desenvolvimento da cotonicultura nacional esteve por muito tempo ancorado na possibilidade de exportação. Contudo, ainda na década de 1960, o Governo Federal passou a promover a exportação de manufaturados com pesados controles sobre as exportações de matérias-primas, entre as quais o algodão. Em 1973, as exportações da pluma também foram proibidas. O objetivo era o atendimento do programa de promoção à exportação de manufaturados. Tal estratégia perdurou até 1988. Esses acontecimentos, aliados às infestações de pragas em regiões tradicionais de cultivo e perda de competitividade frente à pluma importada, entre outros fatores, contribuíram para que a produção nacional de algodão sofresse decréscimos expressivos de área e produção. 
Aos poucos as restrições foram perdendo força, mormente no início de 1990, quando a abertura comercial do país se intensificou. A partir de então a cotonicultura passou a apresentar sinais de recuperação e melhorar a competitividade. A produção nacional de algodão, que ocorria sob cultivo tradicional (intensivo em mão-de-obra) principalmente nas Regiões Sul e Sudeste do país (Estados de São Paulo e Paraná), passou a se desenvolver empresarialmente se estendendo principalmente para a região CentroOeste do país (Estados de Mato Grosso, Goiás e Mato Grosso do Sul), mas avançando também para algumas outras regiões, como a Sudeste (Minas Gerais) e Nordeste (Bahia). O avanço da produção esteve ancorado num novo sistema produtivo baseado em grandes extensões de áreas e mecanizado do plantio à colheita. Com isso, a produtividade brasileira deu um grande salto, ultrapassando as médias obtidas pelos principais países produtores. Atualmente, a produção interna gera excedente de exportação considerável; o Brasil passou a ter uma importante participação no cenário mundial tanto em termos de produção como de exportação.

Desenvolve-se um modelo econômico que possibilite aferir o crescimento do setor de algodão em termos de choques de oferta e de demanda, com implementação através de análise de séries temporais. Muitos fatores podem ter contribuído para o crescimento da produção brasileira no período sob análise. Entretanto, não se pretende identificar detalhadamente os efeitos de instrumentos e/ou eventos específicos, que possam circunstancialmente afetar o desempenho do setor. A idéia é a de que eventos específicos influenciem o crescimento setorial por meio de deslocamentos da demanda ou da oferta.

\section{REVISÃO BIBLIOGRÁFICA}

Vários trabalhos analisam o crescimento do produto, interpretando-o em termos de choques de oferta e de demanda, assim como entre efeitos permanentes e temporários. ${ }^{1}$ Os primeiros trabalhos tinham como foco a análise do produto macroeconômico, sendo que os trabalhos em nível setorial foram sendo elaborados posteriormente.

Tradicionalmente, as flutuações do produto eram vistas como sendo temporárias, evoluindo ao longo de uma tendência determinística. Trabalhos mais recentes, como Blanchard e Quah (1989), apontam que o produto é afetado por dois tipos de choques - de demanda e de oferta - estocásticos com efeitos permanentes e temporários. Choques de efeito permanente têm sido associados a inovações tecnológicas, cujo efeito cumulativo é responsável pela maior parte das flutuações econômicas.

Segundo Ruttan (2002), no início do século XX a maior parte do crescimento da produção de grãos e do setor animal decorreu do acréscimo de área cultivada; na segunda metade do século XX a quase totalidade dos aumentos de produção ocorreu em virtude dos ganhos de produtividade por área plantada. Shane et alii (1998) analisaram as fontes de crescimento do produto agrícola dos EUA, utilizando a metodologia tradicional de função de produção, assim como medindo o crescimento da produtividade através do resíduo de Solow (razão do crescimento do índice de produto agregado sobre o de insumo agregado), entre as décadas de 1950 e 1990 . O crescimento da produtividade foi o fator predominante no crescimento do produto. Outros trabalhos nessa linha são, por exemplo, Gopinath e Roe (1997), Martin e Mitra (1999), Gasques et alii (2003), Oehmke e Schimmelpfennig (2004), Ledena e Hertel (2006), entre outros.

Barros et alii (2006) analisaram o padrão de crescimento da agricultura brasileira entre os anos de 1967 e 2003 em termos choques de oferta (produtividade) e de demanda (mercados interno e externo). Desenvolveram um modelo econômico para o setor agrícola usando, segundo os autores, as mesmas idéias de Blanchard e Quah (1989) e que foi estimado com o método VAR Estrutural. As variáveis utilizadas no modelo foram o Produto Interno Bruto - PIB, a taxa de câmbio, a produtividade da terra, a produção agregada das lavouras, a produtividade da terra e o preço médio dos produtos. Os choques de oferta e de demanda mostraram efeitos permanentes sobre o produto agrícola e preços. A maior parte

${ }^{1}$ Citam-se, entre outros, Blanchard e Quah (1989), King et alii (1991), Lima et alii (1992, 1993), Lippi e Reichlin (1993), Blanchard e Quah (1993), Keating e Nye (1998), Cover et alii (2002). 
da explicação do crescimento do produto é atribuída ao avanço na produtividade. A taxa de câmbio foi variável fundamental para a formação dos preços agrícolas e a demanda interna (PIB) mostrou expressiva influência sobre os preços e produto.

\section{MODELO ECONÔMICO}

O modelo aqui apresentado utiliza as idéias básicas desenvolvidas por Barros et alii (2006), que atribuem a evolução da economia a choques de oferta (produtividade) e demanda. Neste caso, pretende-se verificar em que medida o desempenho da produção e da área colhida de algodão no Brasil pode ser atribuído a esses choques. Ao contrário do modelo de Blanchard e Quah (1989), não será imposta restrição de longo prazo para captar os efeitos permanentes e temporários. Sem perda de generalidade, supõem-se elasticidades unitárias nas várias relações envolvidas. Neste modelo, a demanda pelo algodão brasileiro (em logaritmos) é dada por:

$$
y_{t}^{d}=m_{t}-p_{t}
$$

onde $y$ é a quantidade produzida, $m$ a renda nacional real e $p$ é o preço do produto. O produto (em logaritmos) é dado ainda por:

$$
y_{t}^{S}=\eta_{t}+\theta_{t}
$$

em que $\eta$ é a área plantada e $\theta$ a produtividade da terra.

Os impactos no modelo são dados pelos seguintes choques:

a) choques de renda interna $\left(e^{d}\right)$ :

$$
m_{t}=m_{t-1}+e_{t}^{d}
$$

b) choques de produtividade, que afetam a oferta $\left(e^{s}\right)$ :

$$
\theta_{t}=\theta_{t-1}+e_{t}^{S}
$$

c) choques de preços $\left(e^{p}\right)$ :

$$
p_{t}=p_{t-1}+e_{t}^{p}
$$

d) choques de área colhida $\left(e^{\eta}\right)$ :

$$
\eta_{t}=E(p)+e_{t}^{\eta}
$$

sendo

$$
e_{t}^{\eta}=e_{t-1}^{\eta}+u_{t}
$$

Todos os choques - exceto $e_{t}^{\eta}$ - têm média zero, são não-correlacionados e não apresentam autocorrelações.

Além dos choques já descritos, considera-se que a exportação é dada pelo excedente de mercado interno, identificado como:

$$
x_{t}=y_{t}^{5}-y_{t}^{d}
$$

Com esta formulação, a exportação de algodão pelo Brasil só tende a ocorrer se a produção ultrapassar a demanda interna. Nota-se, a propósito, que, sendo exógeno, o preço externo é a variável que determina o montante exportado.

O modelo acima apresentado fundamenta-se em estudo de Barros et alii (2006) que verificaram que, para o conjunto das lavouras brasileiras, o preço doméstico pode ser considerado exógeno em relação à quantidade produzida e consumida e à produtividade. O mesmo foi observado por Coelho (2002), utilizando dados para o período de 1982 a 2001. Interpreta-se essa constatação como evidência de que 
a maioria dos mercados agrícolas nacionais acha-se vinculado ao mercado externo no qual o Brasil comporta-se como tomador de preço. Além disso, admite-se que a área cultivada seja dependente da expectativa de preço para a próxima safra, que, no modelo proposto, é representada pelo preço da safra anterior. Embora tal pressuposto caracterize comportamento não racional do produtor, ele apresenta aderência às observações empíricas. Ver, por exemplo, revisão de literatura de Negri Neto (2001). A produtividade da terra é considerada como dependente do nível alcançado no período anterior, mais choque aleatório, a exemplo de Blanchard e Quah, no caso da produtividade do trabalho.

\subsection{Obtenção da taxa de crescimento das variáveis}

Nesta parte, obtêm-se as expressões que descrevem a taxa de crescimento das variáveis do modelo, em especial as endógenas, como a área, produção e a exportação. Inicialmente, tem-se

$$
E\left(p_{t}\right)=p_{t-1}
$$

que substituindo na equação 6, obtém-se:

$$
\eta_{t}=p_{t-1}+e_{t}^{\eta}
$$

E, usando-se a equação 6' e a equação 2:

$$
y_{t}=p_{t-1}+e_{t}^{\eta}+\theta_{t}
$$

Substituindo a equação 10 e a equação 1 , na equação 8 , pode-se obter:

$$
x_{t}=p_{t-1}+e_{t}^{\eta}+\theta_{t}-m_{t}+p_{t}
$$

Desta forma, a taxa de crescimento do quantum exportado é dada por:

$$
\Delta x_{t}=-e_{t}^{d}+e_{t}^{S}+e_{t}^{p}+e_{t-1}^{p}+\mu_{t}
$$

De acordo com esta expressão, choques na renda nacional tendem a afetar negativamente a exportação de algodão, no sentido de que aumentam a demanda interna pela pluma, reduzindo o excedente exportável. Aumentos de produtividade, por sua vez, favorecem o crescimento da produção, elevando o excedente que poderá ser destinado para o mercado externo. O mesmo ocorre com choques de área colhida. Aumentos no preço também favorecem o crescimento das exportações. Neste caso, é preciso entender que se o preço no mercado interno está crescendo, pela hipótese deste trabalho, isto é o resultado do maior preço externo. Além disso, é preciso ter em conta que o efeito contemporâneo de aumento de preço sobre as exportações se dá pela restrição de consumo interno - e não por aumento na produção. Aumento de preço com uma defasagem também incrementa as exportações, via impacto sobre a área - e, agora sim, sobre a produção - no período seguinte.

A taxa de crescimento da oferta do produto, por sua vez, pode ser obtida aplicando a diferença na equação 10, chegando-se em:

$$
\Delta y_{t}=e_{t}^{S}+\mu_{t}+e_{t-1}^{p}
$$

Observa-se, portanto, que aumentos de produtividade e de área contemporâneos favorecem uma maior oferta do produto. Mas aumentos de preço elevarão a produção no período seguinte, pelo impacto da expectativa de preço sobre a área.

O modelo também permite obter a taxa de crescimento da demanda:

$$
\Delta y_{t}^{d}=e_{t}^{d}-e_{t}^{p}
$$

da produtividade

$$
\Delta \theta_{t}=e_{t}^{S}
$$


da área

$$
\Delta \eta_{t}=e_{t-1}^{p}+\mu_{t}
$$

e da renda:

$$
\Delta m_{t}=e_{t}^{d}
$$

Valem observar os seguintes resultados do modelo:

a) Choque positivo de produtividade, por exemplo, possibilita a elevação da produção no mesmo período do choque, assim como para os períodos seguintes. O efeito é permanente. Além disso, eleva a exportação contemporaneamente, mantendo este nível nos períodos seguintes;

b) Choque de renda interna tende a não alterar a oferta do produto;

c) Choque na área colhida tem um efeito permanente sobre a exportação. Um acréscimo, por exemplo, aumenta o excedente interno, que é destinado ao mercado externo;

d) Uma elevação autônoma do preço interno, ao contrário de reduzir a exportação, favorece o acréscimo do quantum exportado, com efeito permanente sobre esta variável. Isto ocorre em 2 etapas. No mesmo período há uma queda na quantidade demandada internamente resultando numa expansão das exportações. Esse aumento de preço gera aumento de expectativa para o período seguinte, com conseqüente elevação da produção que será canalizada para a exportação, visto que a demanda achase reduzida devido a esse mesmo aumento de preço;

e) A oferta do produto responde com uma defasagem ao choque no preço, posto que este só afeta o produto via efeito sobre a sua expectativa para o período seguinte. Este era um resultado esperado, uma vez que os produtores não conseguem alterar o produto após o plantio da safra, mas somente na safra seguinte, se a perspectiva de preços se manter;

f) Sobre a área, o choque de preço também apresenta um efeito permanente. A resposta ao choque ocorre com uma defasagem, cuja justificativa é a mesma descrita para o produto.

Com estas derivações e analisando os impactos de choques, pode-se construir uma matriz de relações contemporâneas que será utilizada na metodologia VAR, descrita na seção seguinte, como a que segue para a seguinte sequiência de variáveis: renda, produtividade, exportação, produção e preço:

$$
B_{0}=\left[\begin{array}{ccccc}
1 & 0 & 0 & 0 & 0 \\
0 & 1 & 0 & 0 & 0 \\
b_{31} & b_{32} & 1 & b_{34} & b_{35} \\
0 & b_{42} & 0 & 1 & 0 \\
0 & 0 & 0 & 0 & 1
\end{array}\right]
$$

Se ao invés de utilizar a produção obtida, se trabalhar com a área colhida, a seqüência de variáveis se torna: renda, produtividade, exportação, área e preço. A matriz de relações contemporâneas será como a que se segue:

$$
B_{0}=\left[\begin{array}{ccccc}
1 & 0 & 0 & 0 & 0 \\
0 & 1 & 0 & 0 & 0 \\
b_{31} & b_{32} & 1 & b_{34} & b_{35} \\
0 & 0 & 0 & 1 & 0 \\
0 & 0 & 0 & 0 & 1
\end{array}\right]
$$

Em seguida, se descrevem os procedimentos metodológicos que serão utilizados neste trabalho para a análise econométrica do modelo descrito nessa seção. 


\section{PROCEDIMENTOS METODOLÓGICOS}

O modelo econômico proposto e descrito anteriormente terá suas hipóteses testadas através da metodologia de Auto-Regressão Vetorial - VAR, a qual permite a obtenção de elasticidades de impulso para $k$ períodos à frente, possibilitando a avaliação do comportamento das variáveis em resposta a choques (inovações) individuais não-esperados em quaisquer dos componentes do sistema, considerando-se que toda variável possa ser endógena. A decomposição histórica da variância dos erros de previsão, $k$ períodos à frente, trata da análise da importância de cada choque (em cada variável do modelo) na explicação dos desvios dos valores observados das variáveis em relação à sua previsão realizada no início do período considerado.

O modelo conhecido como VAR estrutural, desenvolvido por Bernanke (1986), permite estabelecer relações contemporâneas entre as variáveis tomando a teoria econômica como referência (Hamilton, 1994) de forma a, impondo restrições nas relações contemporâneas entre as variáveis, se obter identificação no modelo empírico (Harvey (1990), Hamilton (1994)). Como o sistema analisado é sobreidentificado, é utilizado o teste da Razão-Verossimilhança (valor da estatística do qui-quadrado para os parâmetros não-restritos) para atestar a validade das estruturas de identificação do modelo teórico (ver Enders (1995)).

Um modelo VAR estrutural pode ser representado por:

$$
\mathbf{B}_{\mathbf{0}} \mathbf{y}_{\mathbf{t}}=\mathbf{B}_{\mathbf{1}} \mathbf{y}_{\mathbf{t}-\mathbf{1}}+\mathbf{B}_{\mathbf{2}} \mathbf{y}_{\mathbf{t}-\mathbf{2}}+\ldots+\mathbf{B}_{\mathbf{p}} \mathbf{y}_{\mathbf{t}-\mathbf{p}}+\mathbf{e}_{\mathbf{t}}
$$

onde $\mathbf{y}_{\mathbf{t}}$ é um vetor com variáveis de interesse; $\mathbf{B}_{\mathbf{j}}$ são matrizes $(n \times n)$ para qualquer $j$, com $\mathbf{B}_{\mathbf{0}}$ sendo a matriz de relações contemporâneas e $\mathbf{e}_{\mathbf{t}}$ é um vetor $n \times 1$ de choques ortogonais. Além de se considerar que os componentes de $\mathbf{e}_{\mathbf{t}}$ são não correlacionados serialmente, adota-se a suposição de que eles não têm causa comum, tratando-os como mutuamente não correlacionados, de tal forma que $E\left(\mathbf{e}_{\mathbf{t}} \mathbf{e}_{\mathbf{t}}{ }^{\prime}\right)=D$.

A equação 18 pode ser escrita como:

$$
\mathbf{B}(L) \mathbf{y}_{\mathbf{t}}=\mathbf{e}_{\mathbf{t}}
$$

onde $\mathbf{B}(L)$ é um polinômio em $L\left(\mathbf{B}_{\mathbf{0}}+\mathbf{B}_{\mathbf{1}} L+\mathbf{B}_{\mathbf{1}} L^{2}+\ldots+\mathbf{B}_{\mathbf{p}} L^{P}\right)$ com $L$ sendo o operador de defasagem tal que $L^{j} y_{t}=y_{t-j}$ para $j$ inteiro.

Para fins de estimação, pré multiplica-se a equação 19 por $\mathbf{B}_{0}{ }^{-1}$ e obtém-se a forma reduzida:

$$
\mathbf{A}(L) \mathbf{y}_{\mathbf{t}}=\mathbf{u}_{\mathbf{t}}
$$

onde $\mathbf{A}(L)=\mathbf{B}_{\mathbf{0}}^{-\mathbf{1}} \mathbf{B}(L), \mathbf{A}_{\mathbf{0}}=\mathbf{I}_{\mathbf{n}}$ e $\mathbf{u}_{\mathbf{t}}=\mathbf{B}_{\mathbf{0}}^{-\mathbf{1}} \mathbf{e}_{\mathbf{t}}$

A equação 20 pode ser estimada pelo Método dos Mínimos Quadrados. Com o uso do procedimento de Bernanke (1986) pode-se estimar, através da maximização do logaritmo da função de verossimilhança, os coeficientes de $\mathbf{B}_{\mathbf{0}}$ e $\mathbf{D}$.

Se o processo é estacionário, a equação 20 pode ser escrita na forma de média móvel (Lütkepohl, 1991):

$$
\mathbf{y}_{\mathbf{t}}=\mathbf{C}(L) \mathbf{u}_{\mathbf{t}}
$$

onde $\mathbf{C}(L)$, que é estimado conhecendo-se $\mathbf{A}(L)$, é um polinômio de ordem infinita de matrizes $C_{j}$.

Escrevendo a equação $21 \mathrm{em}$ termos de $\mathbf{e}_{\mathbf{t}}$ tem-se

$$
\mathbf{y}_{\mathbf{t}}=\mathbf{C}(L) \mathbf{B}_{\mathbf{0}}^{-\mathbf{1}} \mathbf{e}_{\mathbf{t}}
$$

Essa equação pode ser usada para analisar os efeitos dos choques e a decomposição da variância do erro de previsão, isto é, a importância de cada variável em termos da capacidade de explicar a variância dos erros das demais. O modelo, conforme descrito, requer o uso de séries estacionárias ou séries que se tornam estacionárias após a diferenciação. 
Diversos estudos tratam de estabelecer procedimentos para verificar a ordem de integração de uma série temporal. Dentre os procedimentos existentes, os de Dickey e Fuller (1979), complementados pelos de Dickey e Fuller (1979, 1981), tem sido bastante utilizados. O número de raízes unitárias é determinado utilizando o procedimento proposto por Enders (1995).

Se as variáveis são integradas de mesma ordem, um próximo passo seria testar a existência de cointegração entre elas (existência de relação de longo prazo entre as variáveis). A metodologia indicada para modelos com mais de duas variáveis explicativas ou para aqueles nos quais existe endogeneidade dos regressores é a proposta por Johansen (1988). No caso das variáveis serem integradas e cointegradas, termo(s) de correção de erro deve(m) ser utilizado(s) no modelo ajustado com as séries nas diferenças (Engle e Granger (1987), Johansen e Juselius (1990)).

\section{RESULTADOS E DISCUSSÃO}

Dois modelos VAR serão apresentados, um com a área colhida e outro com a quantidade produzida de algodão em caroço, utilizando dados anuais para o período de 1967 a 2004 . Inicialmente, se fará uma análise descritiva dos dados utilizados no trabalho, para em seguida apresentar e analisar os resultados obtidos.

\subsection{Dados utilizados}

O objetivo desta subseção é descrever as variáveis utilizadas de forma a fornecer as principais características do setor no período a ser analisado e apontar alguns aspectos que podem influenciar nos resultados do modelo estimado. As exportações apresentaram grande variabilidade: na segunda metade da década de 1970 decresceram expressivamente, recuperaram-se no início da década de 1980, mas praticamente foram anuladas em meados da década de 1990 (Figura 1). O crescimento das exportações relaciona-se com a retomada da produção interna de algodão. Desta forma, questiona-se até que ponto o acesso ao mercado externo favoreceu o aumento da produção. O estudo da inter-relação entre estas variáveis é foco deste trabalho.

A evolução da produtividade de algodão em caroço foi expressiva (Figura 2) desde meados da década de 1980, coincidindo com a recuperação da produção no mercado interno, com o deslocamento das áreas produtivas para o Centro-Oeste e Nordeste (oeste da Bahia).

A área colhida com algodão decresceu até a segunda metade da década de 1990, se estabilizando e voltando a crescer nos anos seguintes (Figura 3). A produção de algodão em caroço cresceu com oscilações expressivas até início da década de 1990; em seguida, decresceu até 1997 - de menor área colhida e de menor produção (Figura 4). A estabilização da área colhida foi mais do que compensada por ganhos de produtividade, resultando em aumentos expressivos de produção nos anos posteriores.

Os preços ao produtor no mercado interno (Figura 5) cresceram até meados da década de 1970, reduzindo em quase todos os anos seguintes. Em 2004 eles representaram aproximadamente $66 \%$ do que foi recebido em 1967. O acréscimo de produção e ganhos de produtividade são os principais fatores que justificam esta tendência. Contudo, uma questão que se coloca: será que os preços decrescem na mesma proporção em que a produtividade aumenta? A reposta será negativa se o setor de algodão tiver no preço externo sua referência: quer se exporte ou importe, o preço interno tende a convergir para o externo. Não se verificaria perfeita correlação entre esses dois preços devido a interferências governamentais - pontuais ou temporárias - no mercado. Apesar de o Brasil não ter sido um grande player no mercado internacional de exportação, a Figura 6 mostra que as tendências destes preços foram praticamente as mesmas em quase todos os anos analisados, com exceção do período de 1986 a 1993, que coincide com aquele em que havia forte restrição para exportação através de quotas e tarifas (Lopes, 1992). 


\subsection{Propriedades de raiz unitária e de co-integração das variáveis}

Para determinar a ordem do processo auto-regressivo, foram utilizados os critérios de AIC e SC, assim como a análise visual das autocorrelações parciais de cada série. O modelo melhor especificado está apresentado na Tabela 1, com a série produção tendo um processo AR(5), as séries PIB e área colhida sendo um $\operatorname{AR}(3)$ e as demais séries um AR(1). Com esta identificação da ordem do processo auto-regressivo das séries realizou-se o teste de Dickey-Fuller Aumentado - ADF, verificando se a série é estacionária em nível ou nas diferenças. Adotou-se o procedimento sequiencial proposto por Enders (1995) para identificar o modelo específico a ser considerado. Os testes de ADF (Tabela 1) mostram que todas as variáveis são integradas de ordem um $[I(1)]$. Desta forma, na especificação do modelo VAR devem ser consideradas nas diferenças de primeira ordem, conforme recomenda Enders (1995).

Figura 1 - Evolução do índice da exportação de algodão em pluma pelo Brasil

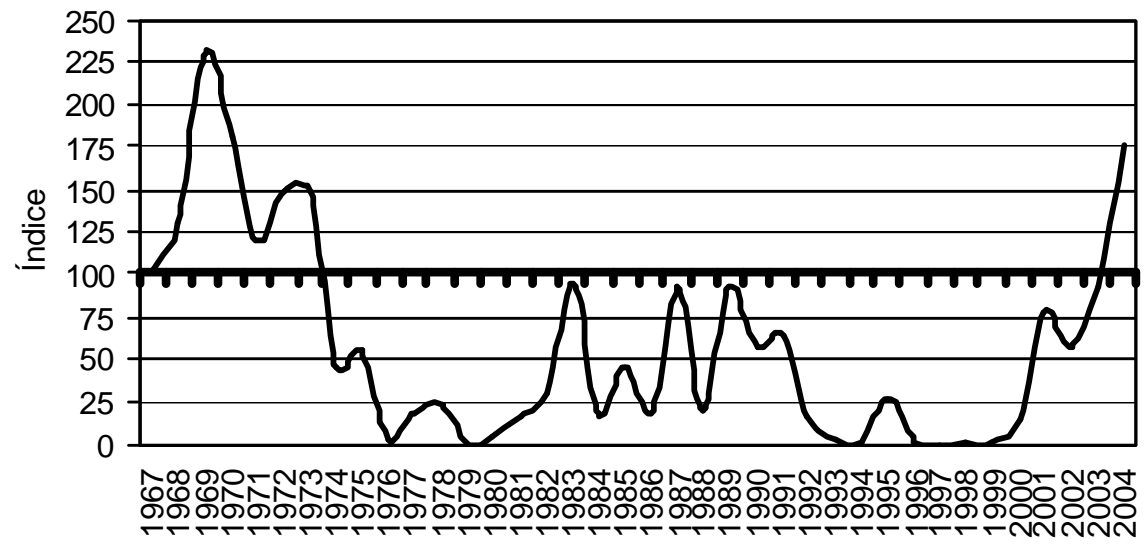

Fonte: Fao (2006).

Sendo todas as séries integradas de mesma ordem, efetuaram-se os testes de co-integração para recuperar as relações de longo prazo das séries. Para isto, dois modelos foram testados. Um englobando a área colhida e outro, a produção de algodão em caroço. O número de defasagem utilizado no teste de co-integração (uma para ambos os modelos) foi definido de acordo com os critérios de AIC e SC para uma versão multiequacional (Tabela 2 e Tabela 3 ). Os testes do máximo autovalor $\left(\gamma_{\max }\right)$ e do traço $\left(\gamma_{\text {trace }}\right)$ indicaram que há três vetores de co-integração nos dois modelos testados. Como o esperado, os resultados mostram que há relações de equilíbrio de longo prazo entre as variáveis. Os modelos a serem ajustados devem, portanto, incluir o termo de Correção de Erro - VEC. Os valores das estatísticas são os mesmos nos dois modelos, com diferenças apenas nos valores dos vetores de co-integração.

\subsection{Modelos de Auto-Regressão Vetorial com Correção de Erro (VEC) com identi- ficação pelo processo de Bernanke}

\subsubsection{Matriz de relações contemporâneas e decomposição da variância do erro da previsão - Modelo com} a área colhida

O primeiro modelo analisado conta com a variável área colhida (ao invés de produção) tendo sido construído com a seguinte seqüência de variáveis: PIB, produtividade agrícola de algodão em caroço, exportação de algodão em pluma, área colhida e preço do algodão em caroço no mercado interno. Além da variável constante e dos três vetores de correção de erro, também se adicionou no modelo uma 
Figura 2 - Evolução do índice da produtividade de algodão em caroço no Brasil

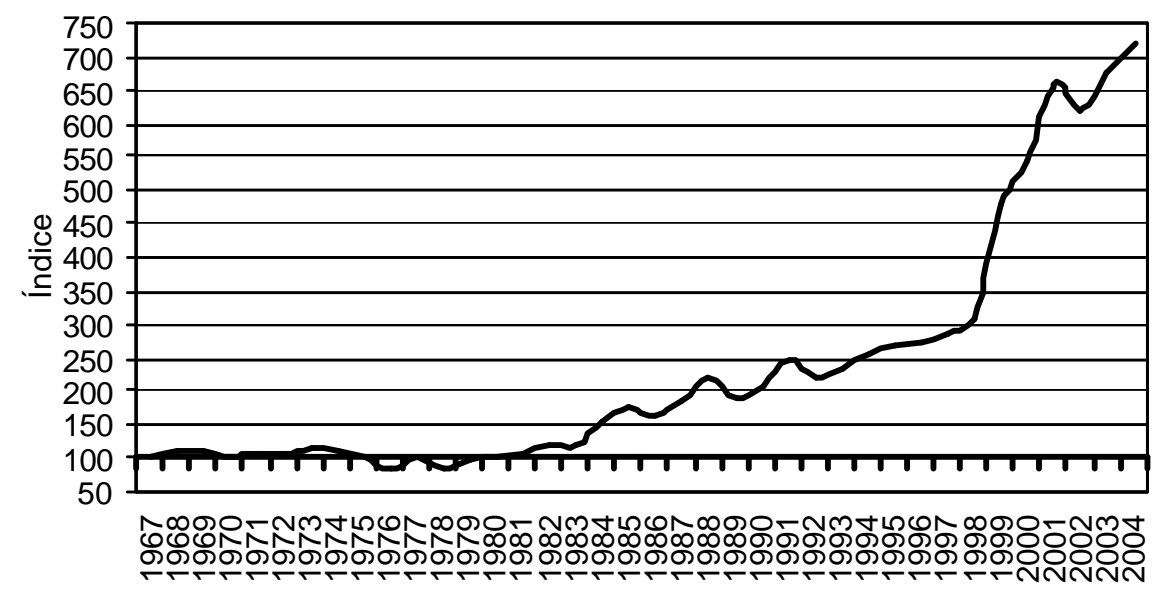

Fonte: Instituto Brasileiro de Geografia e Estatística - IBGE (2005).

Figura 3 - Evolução do índice da área colhida com algodão no Brasil

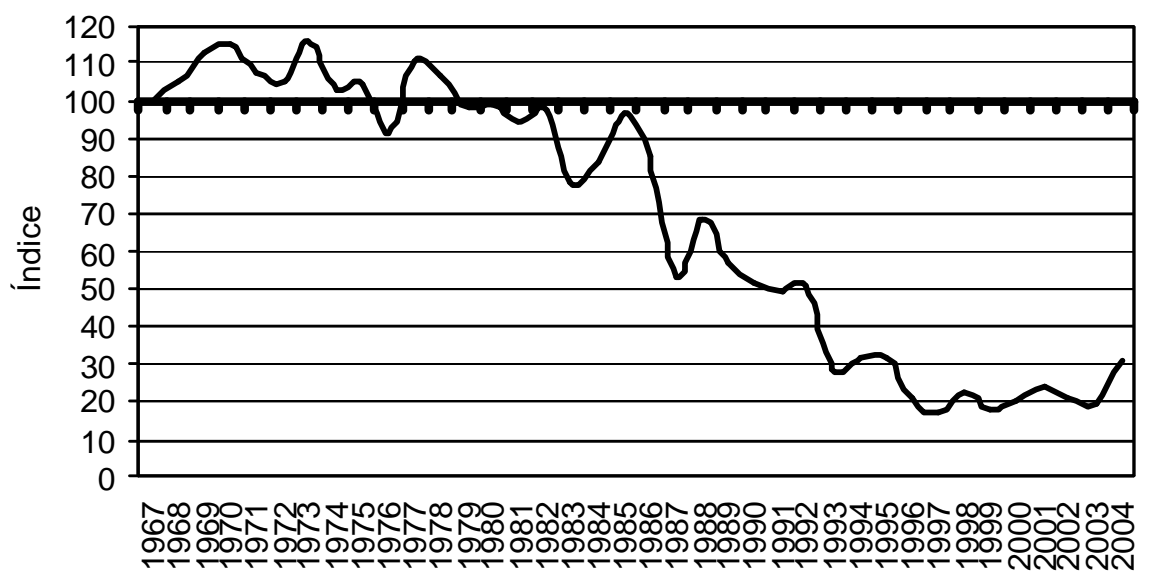

Fonte: Instituto Brasileiro de Geografia e Estatística - IBGE (2005). 
Figura 4 - Evolução do índice da produção de algodão em caroço no Brasil

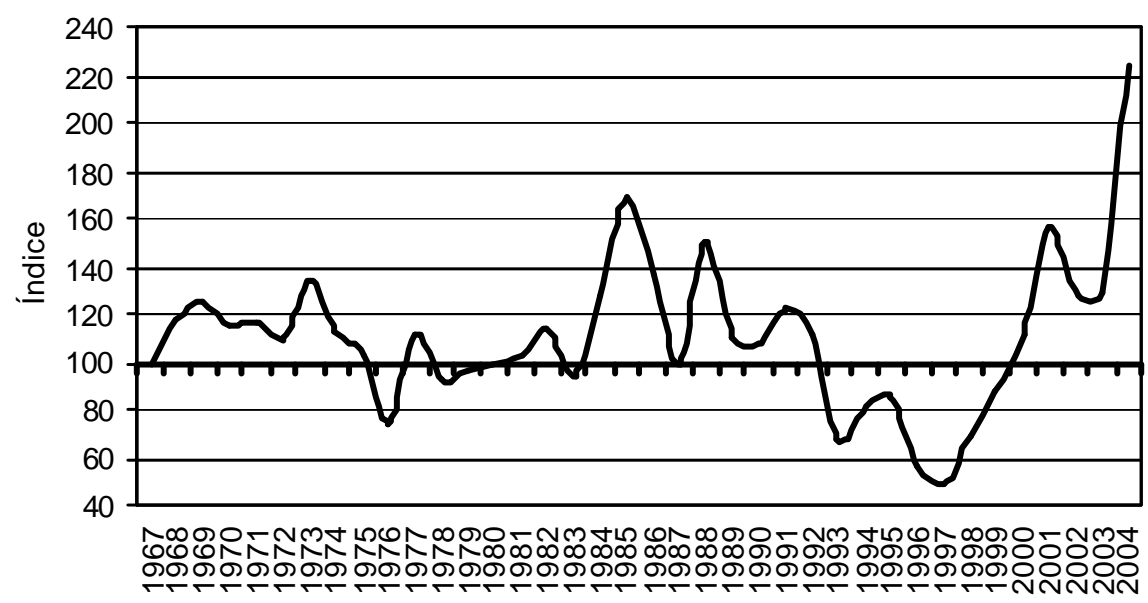

Fonte: Instituto Brasileiro de Geografia e Estatística - IBGE (2005).

Figura 5 - Evolução do índice do preço do algodão em caroço no Brasil - deflacionado pelo Índice Geral de Preços - Disponibilidade Interna (IGP-DI), base $2004=1,00$

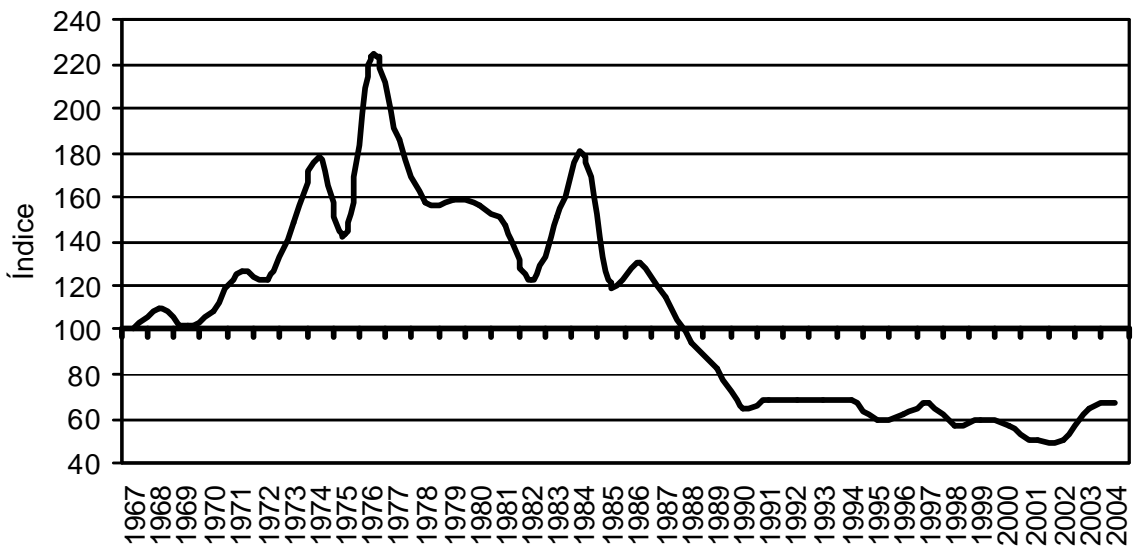

Fonte: Instituto de Pesquisa Econômica Aplicada - IPEA (2005). 
Figura 6 - Evolução dos índices de preços do algodão em caroço e do algodão em pluma exportado pelo Brasil

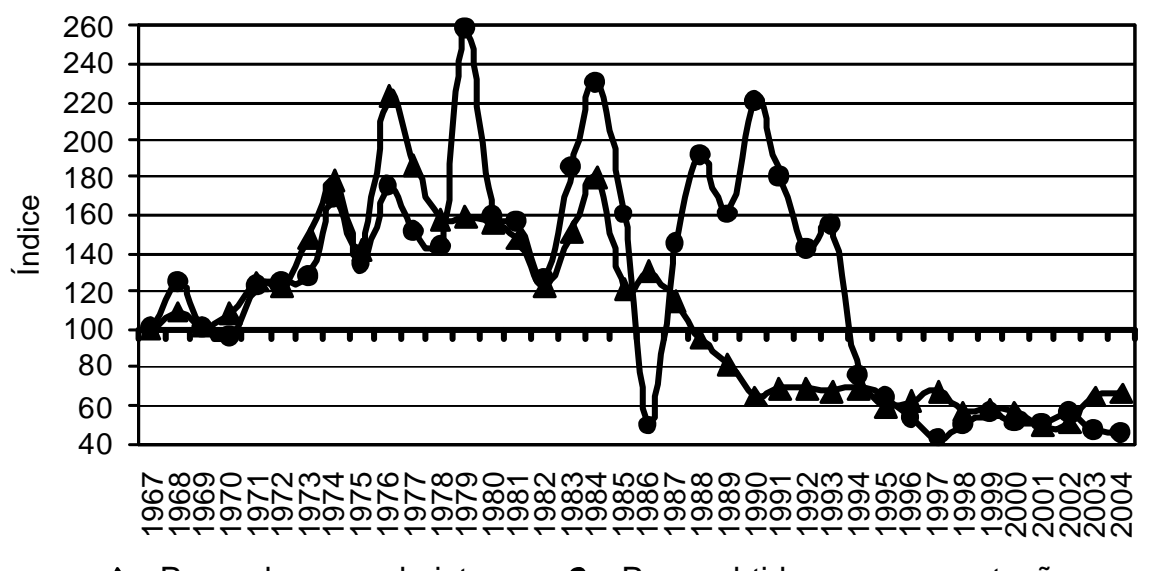

Fonte: Instituto de Pesquisa Econômica Aplicada - IPEA (2006); Fao (2006). Nota: O preço interno foi deflacionado pelo Índice Geral de Preços - Disponibilidade Interna (IGP-DI), base $2004=1,00$ (Instituto de Pesquisa Econômica Aplicada - IPEA, 2006). O preço recebido pelo produtor nacional com a exportação do algodão em pluma foi obtido através da multiplicação do preço recebido em dólar pela taxa de câmbio do período, e em seguida fez-se o deflacionamento pelo IGP-DI, base 2004=1,00.

Tabela 1 - Resultados dos testes de raiz unitária de Dickey-Fuller para as séries PIB do Brasil, produção de algodão em caroço, área colhida com algodão no Brasil, produtividade de algodão em caroço, quantidade exportada de algodão em pluma e preço do algodão em caroço ao produtor

\begin{tabular}{|l|c|c|c|c|c|c|c|}
\hline \multirow{2}{*}{ Variáveis } & Valor & \multicolumn{5}{|c|}{ Modelo 1 } & Modelo 2 $^{c}$ \\
\cline { 3 - 8 } & de p-1 & $\tau_{\tau}$ & $\tau_{\beta \tau}$ & $\tau_{\mu}$ & $\tau_{\alpha \mu}$ & $\tau$ & $\tau$ \\
\hline PIB & 2 & $-3,280$ & 2,178 & $-2,826$ & 2,925 & 1,280 & $-1,764^{b}$ \\
Produção & 4 & $-2,317$ & $-0,096$ & $-2,659$ & 2,674 & 0,308 & $-2,026^{a}$ \\
Produtividade & 0 & $-1,535$ & 2,127 & 1,005 & $-0,697$ & 2,701 & $-5,707^{a}$ \\
Quant. export & 0 & $-2,865$ & $-0,507$ & $-2,928$ & 2,518 & $-1,394$ & $-7,984^{a}$ \\
Preço interno & 0 & $-2,462$ & $-2,356$ & $-0,948$ & 0,906 & $-0,493$ & $-7,339^{a}$ \\
Área colhida & 2 & $-1,684$ & $-1,757$ & $-0,115$ & $-0,240$ & $-2,172$ & $-5,600^{a}$ \\
\hline
\end{tabular}

Fonte: Dados da pesquisa; Nota: Não houve presença de autocorrelação serial, conforme o teste de $Q$ de Lung Box.

${ }^{a}$ Significativo ao nível de $1 \%$ de significância.

${ }^{b}$ Significativo ao nível de 10\% de significância (valores críticos em Dickey e Fuller (1979) e Dickey e Fuller (1981)). Modelo $1=\Delta x_{t}=\alpha+\beta t+\gamma x_{t-1}+\sum_{i=1}^{p-1} \lambda_{i} \Delta x_{t-i}+\epsilon_{t}$, nas versões com constante e tendência, sem tendência e sem tendência e constante.

${ }^{c}$ Modelo 2 $=\Delta \Delta x_{t}=\gamma \Delta x_{t-1}+\sum_{i=1}^{p-2} \lambda_{i} \Delta \Delta x_{t-i}+\epsilon_{t}$, definido após constatado a não existência de termos deterministas. 
Tabela 2 - Modelo com a área colhida de algodão - Resultados dos testes de co-integração de Johansen entre as séries PIB do Brasil, área colhida com algodão no Brasil, produtividade de algodão em caroço, quantidade exportada de algodão em pluma e preço do algodão em caroço ao produtor

\begin{tabular}{|l|c|c|c|}
\hline Hipótese Nula & Hipótese Alternativa & $\lambda_{\max }$ & $\lambda_{\text {trace }}$ \\
\hline $\mathrm{r} \leq 4$ & $\mathrm{r}=5$ & 4,28 & 4,28 \\
$\mathrm{r} \leq 3$ & $\mathrm{r}=4$ & 12,58 & 16,86 \\
$\mathrm{r} \leq 2$ & $\mathrm{r}=3$ & $22,53^{*}$ & $39,39^{*}$ \\
$\mathrm{r} \leq 1$ & $\mathrm{r}=2$ & $34,45^{*}$ & $73,84^{*}$ \\
$\mathrm{r} \leq 0$ & $\mathrm{r}=1$ & $72,32^{*}$ & $146,15^{*}$ \\
\hline
\end{tabular}

Fonte: Dados da pesquisa. ${ }^{*}$ Significativo a 5\% (valores críticos em Osterwald-Lenum (1992). Tabela 1). Modelo com constante restrita, ajustado com uma defasagem.

Tabela 3 - Modelo com a produção de algodão - Resultados dos testes de co-integração de Johansen entre as séries PIB do Brasil, produção de algodão em caroço, produtividade de algodão em caroço, quantidade exportada de algodão em pluma e preço do algodão em caroço ao produtor

\begin{tabular}{l|c|c|c|}
\hline Hipótese Nula & Hipótese Alternativa & $\lambda_{\{\max }$ & $\lambda_{\text {trace }}$ \\
\hline $\mathrm{r} \leq 4$ & $\mathrm{r}=5$ & 4,28 & 4,28 \\
$\mathrm{r} \leq 3$ & $\mathrm{r}=4$ & 12,58 & 16,86 \\
$\mathrm{r} \leq 2$ & $\mathrm{r}=3$ & $22,53^{*}$ & $39,39 *$ \\
$\mathrm{r} \leq 1$ & $\mathrm{r}=2$ & $34,45^{*}$ & $73,84^{*}$ \\
$\mathrm{r} \leq 0$ & $\mathrm{r}=1$ & $72,32^{*}$ & $146,15^{*}$ \\
\hline
\end{tabular} Fonte: Dados da pesquisa.
* Significativo a 5\% (valores críticos em Osterwald-Lenum (1992) - Tabela 1*).
Modelo com constante restrita, ajustado com uma defasagem.

variável binária, com valor um do ano de 1986 a 1993, tentando captar diferenças no período em que os preços internos e os recebido pela exportação apresentaram divergências mais expressivas, já tratadas anteriormente.

Conforme se observa na Tabela 4, a estimativa do teste da Razão-Verossimilhança não rejeitou a hipótese sobre a validade das restrições e os sinais de todos os coeficientes na matriz de relações contemporâneas estão de acordo com o esperado. Estes devem ser analisados ao contrário do que apresentado pelo modelo. Os valores dos coeficientes também foram expressivos, apontando para a importante influência contemporânea do PIB, da produtividade e da área colhida sobre a exportação.

Tabela 4 - Estimativa da matriz de coeficientes de relações contemporâneas, para o modelo com a área colhida

\begin{tabular}{|c|c|c|c|}
\hline \multicolumn{2}{|c|}{ Influência: } & Coeficiente & Nível de \\
\hline $\mathrm{De}$ & Sobre & Estimado & Significância \\
\hline PIB & Exportação & 6,219 & 0,170 \\
\hline Produtividade & Exportação & $-6,286$ & 0,000 \\
\hline Área & Exportação & $-5,533$ & 0,000 \\
\hline Preço interno & Exportação & 0,773 & 0,521 \\
\hline
\end{tabular}

Fonte: Dados da pesquisa. Obs.: Teste de Razão-Verossimilhança para sobreidentificação: $\chi^{2}(5)=7,3702(0,1945)$.

Em seguida, se analisa a decomposição histórica da variância do erro de previsão de cada variável para este modelo que inclui a variável área colhida. Na Tabela $5^{2}$ analisa-se a decomposição para a

\footnotetext{
${ }^{2}$ Os doze períodos apresentados nas tabelas foram definidos de forma aleatória.
} 
variável PIB, que se revelou exógena em relação às demais do modelo, com praticamente $91 \%$ de suas variações sendo explicadas por ela mesma a partir do terceiro ano após o choque. Este resultado está de acordo com as expectativas de maior influência do PIB sobre as demais variáveis do que o contrário. Da mesma forma, verifica-se que a mesma exogeneidade foi observada para a produtividade (Tabela 6) e preço interno (Tabela 7).

Corroborando o modelo econômico, a decomposição da variância do erro de previsão do quantum exportado se mostrou dependente principalmente da produtividade e da área plantada. O preço tem um papel secundário. A própria variável explica aproximadamente 1/4 de suas variações ao longo do período (Tabela 8).

Em suma, são os choques de oferta (produtividade e área) que contribuem para explicar variações da exportação - de $70 \%$ a $62 \%$ das variações do quantum exportado é explicado pela produtividade e a área.

Tabela 5 - Decomposição histórica da variância do erro de previsão para o PIB do Brasil - Modelo com a área colhida

\begin{tabular}{|c|c|c|c|c|c|c|}
\hline Anos & Desvio-padrão & \multicolumn{5}{|c|}{ Decomposição da variância devida a choques em (\%) } \\
\cline { 3 - 7 } & & PIB & PRODT & EXP & AREA & PR INT \\
\hline 1 & 0,023 & 100,000 & 0,000 & 0,000 & 0,000 & 0,000 \\
2 & 0,025 & 91,855 & 0,051 & 6,731 & 0,765 & 0,597 \\
3 & 0,025 & 91,185 & 0,233 & 6,948 & 1,028 & 0,606 \\
4 & 0,025 & 91,022 & 0,239 & 6,964 & 1,073 & 0,702 \\
5 & 0,025 & 90,972 & 0,251 & 6,963 & 1,076 & 0,739 \\
6 & 0,025 & 90,961 & 0,254 & 6,963 & 1,075 & 0,747 \\
7 & 0,025 & 90,959 & 0,254 & 6,964 & 1,075 & 0,748 \\
8 & 0,025 & 90,959 & 0,254 & 6,964 & 1,075 & 0,748 \\
9 & 0,025 & 90,959 & 0,254 & 6,964 & 1,075 & 0,748 \\
10 & 0,025 & 90,959 & 0,254 & 6,964 & 1,075 & 0,748 \\
11 & 0,025 & 90,959 & 0,254 & 6,964 & 1,075 & 0,748 \\
12 & 0,025 & 90,959 & 0,254 & 6,964 & 1,075 & 0,748 \\
\hline
\end{tabular}

Fonte: Dados da pesquisa.

Tabela 6 - Decomposição histórica da variância do erro de previsão para a produtividade do algodão em caroço no Brasil - Modelo com a área colhida

\begin{tabular}{|c|c|c|c|c|c|c|}
\hline \multirow{2}{*}{ Anos } & Desvio-padrão & \multicolumn{5}{|c|}{ Decomposição da variância devida a choques em (\%) } \\
\cline { 3 - 7 } & & PIB & PRODT & EXP & AREA & PR INT \\
\hline 1 & 0,100 & 0,000 & 100,000 & 0,000 & 0,000 & 0,000 \\
2 & 0,105 & 2,438 & 92,501 & 0,848 & 0,263 & 3,949 \\
3 & 0,106 & 2,414 & 91,607 & 0,875 & 0,264 & 4,840 \\
4 & 0,106 & 2,408 & 91,381 & 0,893 & 0,272 & 5,047 \\
5 & 0,106 & 2,407 & 91,344 & 0,898 & 0,273 & 5,078 \\
6 & 0,106 & 2,407 & 91,338 & 0,900 & 0,273 & 5,083 \\
7 & 0,106 & 2,407 & 91,336 & 0,900 & 0,273 & 5,083 \\
8 & 0,106 & 2,407 & 91,336 & 0,900 & 0,273 & 5,084 \\
9 & 0,106 & 2,407 & 91,336 & 0,900 & 0,273 & 5,084 \\
10 & 0,106 & 2,407 & 91,336 & 0,900 & 0,273 & 5,084 \\
11 & 0,106 & 2,407 & 91,336 & 0,900 & 0,273 & 5,084 \\
12 & 0,106 & 2,407 & 91,336 & 0,900 & 0,273 & 5,084 \\
\hline
\end{tabular}

Fonte: Dados da pesquisa.

A área colhida - também conforme a derivação do modelo econômico - se mostrou exógena, com pequena importância da produtividade e do preço interno em explicar suas variações (Tabela 9). Essa 
Tabela 7 - Decomposição histórica da variância do erro de previsão do preço do algodão em caroço no Brasil - Modelo com a área colhida

\begin{tabular}{|c|c|c|c|c|c|c|}
\hline Anos & Desvio-padrão & \multicolumn{5}{|c|}{ Decomposição da variância devida a choques em (\%) } \\
\cline { 3 - 7 } & & PIB & PRODT & EXP & AREA & PR INT \\
\hline 1 & 0,094 & 0,000 & 0,000 & 0,000 & 0,000 & 100,000 \\
2 & 0,105 & 1,398 & 1,675 & 0,147 & 1,095 & 95,686 \\
3 & 0,106 & 1,403 & 1,780 & 0,397 & 1,438 & 94,981 \\
4 & 0,107 & 1,407 & 1,775 & 0,480 & 1,460 & 94,878 \\
5 & 0,107 & 1,412 & 1,775 & 0,496 & 1,459 & 94,858 \\
6 & 0,107 & 1,413 & 1,775 & 0,498 & 1,459 & 94,855 \\
7 & 0,107 & 1,413 & 1,775 & 0,499 & 1,459 & 94,855 \\
8 & 0,107 & 1,413 & 1,775 & 0,499 & 1,459 & 94,855 \\
9 & 0,107 & 1,413 & 1,775 & 0,499 & 1,459 & 94,855 \\
10 & 0,107 & 1,413 & 1,775 & 0,499 & 1,459 & 94,855 \\
11 & 0,107 & 1,413 & 1,775 & 0,499 & 1,459 & 94,855 \\
12 & 0,107 & 1,413 & 1,775 & 0,499 & 1,459 & 94,855 \\
\hline
\end{tabular}

Fonte: Dados da pesquisa.

Tabela 8 - Decomposição histórica da variância do erro de previsão para a exportação de algodão em pluma do Brasil - Modelo com a área colhida

\begin{tabular}{|c|c|c|c|c|c|c|}
\hline \multirow{2}{*}{ Anos } & Desvio-padrão & \multicolumn{5}{|c|}{ Decomposição da variância devida a choques em (\%) } \\
\cline { 3 - 7 } & & PIB & PRODT & EXP & ÁREA & PR INT \\
\hline 1 & 1,156 & 1,587 & 29,748 & 28,642 & 39,631 & 0,392 \\
2 & 1,251 & 4,009 & 28,808 & 26,094 & 34,059 & 7,031 \\
3 & 1,264 & 4,642 & 28,596 & 25,627 & 33,838 & 7,297 \\
4 & 1,264 & 4,642 & 28,570 & 25,606 & 33,892 & 7,290 \\
5 & 1,264 & 4,644 & 28,574 & 25,601 & 33,886 & 7,294 \\
6 & 1,264 & 4,645 & 28,575 & 25,600 & 33,885 & 7,294 \\
7 & 1,264 & 4,645 & 28,575 & 25,600 & 33,885 & 7,294 \\
8 & 1,264 & 4,645 & 28,575 & 25,600 & 33,885 & 7,294 \\
9 & 1,264 & 4,645 & 28,575 & 25,600 & 33,885 & 7,294 \\
10 & 1,264 & 4,645 & 28,575 & 25,600 & 33,885 & 7,294 \\
11 & 1,264 & 4,645 & 28,575 & 25,600 & 33,885 & 7,294 \\
12 & 1,264 & 4,645 & 28,575 & 25,600 & 33,885 & 7,294 \\
\hline
\end{tabular}

exogeneidade da área em relação às demais do modelo parece apontar para o fato de que após a entrada do produtor nesta cultura, sua saída não se dá de maneira rápida. Esta cultura é exigente em insumos específicos, tanto variáveis quanto fixos, com pesada participação de custos irrecuperáveis (sunk cost), os quais reduzem a margem de ajustes dos produtores a preços.

\subsubsection{Matriz de relações contemporâneas e decomposição da variância do erro da previsão - Modelo com a produção de algodão em caroço}

Nesta subseção se analisam os resultados da decomposição da variância dos erros de previsão para o modelo no qual se substitui a variável área pela produção de algodão em caroço. As variáveis foram ordenadas como segue: PIB, produtividade do algodão em caroço, exportação de algodão em pluma, produção de algodão em caroço e preço do algodão em caroço no mercado interno. Os resultados da estimativa são apresentados na Tabela 10.

Da mesma forma que o modelo anterior, a estimativa do teste da Razão-Verossimilhança atesta a validade da estrutura de identificação encontrada aos níveis de significância usuais e os sinais de todos os coeficientes estão de acordo com o esperado. Coeficientes significativos foram encontrados na in- 
Tabela 9 - Decomposição histórica da variância do erro de previsão para a área colhida com algodão (herbáceo e arbóreo) no Brasil - Modelo com a área colhida

\begin{tabular}{|c|c|c|c|c|c|c|}
\hline Anos & Desvio-padrão & \multicolumn{5}{|c|}{ Decomposição da variância devida a choques em (\%) } \\
\cline { 3 - 7 } & & PIB & PRODT & EXP & ÁREA & PR INT \\
\hline 1 & 0,132 & 0,000 & 0,000 & 0,000 & 100,000 & 0,000 \\
2 & 0,146 & 0,052 & 9,266 & 0,206 & 83,324 & 7,153 \\
3 & 0,149 & 0,398 & 10,571 & 0,232 & 80,692 & 8,107 \\
4 & 0,149 & 0,409 & 10,687 & 0,266 & 80,434 & 8,204 \\
5 & 0,149 & 0,409 & 10,690 & 0,275 & 80,415 & 8,211 \\
6 & 0,149 & 0,409 & 10,690 & 0,277 & 80,412 & 8,212 \\
7 & 0,149 & 0,409 & 10,690 & 0,277 & 80,412 & 8,212 \\
8 & 0,149 & 0,409 & 10,690 & 0,277 & 80,412 & 8,213 \\
9 & 0,149 & 0,409 & 10,690 & 0,277 & 80,411 & 8,213 \\
10 & 0,149 & 0,409 & 10,690 & 0,277 & 80,411 & 8,213 \\
11 & 0,149 & 0,409 & 10,690 & 0,277 & 80,411 & 8,213 \\
12 & 0,149 & 0,409 & 10,690 & 0,277 & 80,411 & 8,213 \\
\hline
\end{tabular}

fluência do PIB e da produção sobre a exportação. Entretanto, o modelo apontou uma menor influência da produtividade sobre a exportação. Este resultado parece estar ligado à importante influência da produtividade sobre a produção e desta sobre a exportação. Como a produtividade e a produção apresentam alta correlação, foi a produção que se mostrou mais forte em influenciar a exportação. Vale ressaltar, entretanto, que o coeficiente da produção sobre a exportação é igual ao da área sobre a exportação.

Tabela 10 - Estimativa da matriz de coeficientes de relações contemporâneas, para o modelo com a produção de algodão em caroço

\begin{tabular}{|c|c|c|c|}
\hline \multicolumn{2}{|c|}{ Influência: } & \multirow{2}{*}{$\begin{array}{l}\text { Coeficiente } \\
\text { Estimado }\end{array}$} & \multirow{2}{*}{$\begin{array}{c}\text { Nível de } \\
\text { Significância }\end{array}$} \\
\hline De & Sobre & & \\
\hline PIB & Exportação & 6,219 & 0,167 \\
\hline Produtividade & Exportação & $-0,753$ & 0,587 \\
\hline Produção & Exportação & $-5,533$ & 0,000 \\
\hline Preço interno & Exportação & 0,773 & 0,524 \\
\hline Produtividade & Produção & $-0,849$ & 0,000 \\
\hline
\end{tabular}

Em termos gerais, a decomposição histórica da variância do erro de previsão deste modelo não mostrou divergência em relação ao obtido no modelo com a área colhida, apontando para a estabilidade dos modelos analisados. Mesmo com alteração das variáveis, as influências entre as mesmas não sofrem alterações.

Na Tabela 11 a decomposição da variância do PIB mostra sua exogeneidade em relação às demais do modelo. A série de produtividade também continua sendo exógena, sofrendo apenas pequenas influências do preço interno (Tabela 12). Na Tabela 13 também pode-se observar que a decomposição da variância do erro de previsão do preço interno não se alterou, apontando que o mesmo é exógeno a choques das demais variáveis do modelo.

A decomposição da variância do quantum exportado continuou apontando para sua dependência em relação às demais variáveis do modelo (Tabela 14). Variações de produtividade e de produção foram mais expressivas na explicação das variações da exportação, mas o preço interno e a renda interna também se mostraram relevantes.

Desta forma, as exportações oscilam mais em virtude de fatores relacionados à oferta do produto (produtividade) e de excedente de mercado interno (maior produção). Fatores relacionados à demanda 
interna e preços são secundários em explicar a decomposição da variância do erro de previsão da série.

Tabela 11 - Decomposição histórica da variância do erro de previsão para o PIB do Brasil - Modelo com a produção de algodão

\begin{tabular}{|c|c|c|c|c|c|c|}
\hline Anos & Desvio-padrão & \multicolumn{5}{|c|}{ Decomposição da variância devida a choques em (\%) } \\
\cline { 3 - 7 } & & PIB & PRODT & EXP & PRODUÇAO & PR INT \\
\hline 1 & 0,023 & 100,000 & 0,000 & 0,000 & 0,000 & 0,000 \\
2 & 0,025 & 91,897 & 0,016 & 6,735 & 0,756 & 0,597 \\
3 & 0,025 & 91,273 & 0,150 & 6,955 & 1,016 & 0,607 \\
4 & 0,025 & 91,106 & 0,161 & 6,971 & 1,060 & 0,703 \\
5 & 0,025 & 91,054 & 0,174 & 6,970 & 1,062 & 0,740 \\
6 & 0,025 & 91,043 & 0,178 & 6,970 & 1,062 & 0,747 \\
7 & 0,025 & 91,042 & 0,178 & 6,970 & 1,062 & 0,748 \\
8 & 0,025 & 91,041 & 0,178 & 6,970 & 1,062 & 0,748 \\
9 & 0,025 & 91,041 & 0,178 & 6,970 & 1,062 & 0,749 \\
10 & 0,025 & 91,041 & 0,178 & 6,970 & 1,062 & 0,749 \\
11 & 0,025 & 91,041 & 0,178 & 6,970 & 1,062 & 0,749 \\
12 & 0,025 & 91,041 & 0,178 & 6,970 & 1,062 & 0,749 \\
\hline
\end{tabular}

Fonte: Dados da pesquisa

Tabela 12 - Decomposição histórica da variância do erro de previsão para a produtividade do algodão em caroço no Brasil - Modelo com a produção de algodão

\begin{tabular}{|c|c|c|c|c|c|c|}
\hline Anos & Desvio-padrão & \multicolumn{5}{|c|}{ Decomposição da variância devida a choques em (\%) } \\
\cline { 3 - 7 } & & PIB & PRODT & EXP & PRODUÇÃO & PR INT \\
\hline 1 & 0,100 & 0,000 & 100,000 & 0,000 & 0,000 & 0,000 \\
2 & 0,105 & 2,435 & 92,516 & 0,847 & 0,260 & 3,943 \\
3 & 0,106 & 2,411 & 91,623 & 0,873 & 0,260 & 4,833 \\
4 & 0,106 & 2,405 & 91,397 & 0,891 & 0,268 & 5,040 \\
5 & 0,106 & 2,404 & 91,360 & 0,897 & 0,269 & 5,070 \\
6 & 0,106 & 2,404 & 91,354 & 0,898 & 0,269 & 5,075 \\
7 & 0,106 & 2,404 & 91,353 & 0,899 & 0,269 & 5,076 \\
8 & 0,106 & 2,404 & 91,352 & 0,899 & 0,269 & 5,076 \\
9 & 0,106 & 2,404 & 91,352 & 0,899 & 0,269 & 5,076 \\
10 & 0,106 & 2,404 & 91,352 & 0,899 & 0,269 & 5,076 \\
11 & 0,106 & 2,404 & 91,352 & 0,899 & 0,269 & 5,076 \\
12 & 0,106 & 2,404 & 91,352 & 0,899 & 0,269 & 5,076 \\
\hline
\end{tabular}

Fonte: Dados da pesquisa

A produção de algodão em caroço se mostrou mais dependente das demais variáveis, comparativamente à área colhida, particularmente de choques de oferta (produtividade) e de preços que tiveram influências relevantes sobre a produção. Fatores relacionados à demanda, seja do mercado interno (PIB) ou do externo (exportação), não se mostraram importantes em explicar variações da produção (Tabela 15). A participação da própria variável na decomposição da sua variância é de praticamente $56 \%$ a partir do terceiro período, ou seja, há uma expressiva exogeneidade da produção. A produtividade explica aproximadamente $28 \%$ das variações na produção, enquanto a participação dos preços apresenta ligeiros acréscimos até o quinto período após o choque, explicando mais de $14 \%$ das variações da produção.

Aparentemente há necessidade de um período de ajustamento para que os produtores tomem a decisão de plantar ou não: preços favoráveis em um ano tendem a atrair os produtores para a cultura no ano seguinte, se a expectativa de preços atraentes se mantiver. 
Tabela 13 - Decomposição histórica da variância do erro de previsão do preço do algodão em caroço no Brasil - Modelo com a produção de algodão

\begin{tabular}{|c|c|c|c|c|c|c|}
\hline \multirow{2}{*}{ Anos } & Desvio-padrão & \multicolumn{5}{|c|}{ Decomposição da variância devida a choques em (\%) } \\
\cline { 3 - 7 } & & PIB & PRODT & EXP & PRODUÇAO & PR INT \\
\hline 1 & 0,094 & 0,000 & 0,000 & 0,000 & 0,000 & 100,000 \\
2 & 0,105 & 1,403 & 1,381 & 0,147 & 1,083 & 95,986 \\
3 & 0,106 & 1,409 & 1,446 & 0,398 & 1,424 & 95,323 \\
4 & 0,106 & 1,412 & 1,442 & 0,482 & 1,445 & 95,218 \\
5 & 0,106 & 1,417 & 1,442 & 0,498 & 1,445 & 95,198 \\
6 & 0,106 & 1,418 & 1,442 & 0,500 & 1,445 & 95,196 \\
7 & 0,106 & 1,418 & 1,442 & 0,501 & 1,445 & 95,195 \\
8 & 0,106 & 1,418 & 1,442 & 0,501 & 1,445 & 95,195 \\
9 & 0,106 & 1,418 & 1,442 & 0,501 & 1,445 & 95,195 \\
10 & 0,106 & 1,418 & 1,442 & 0,501 & 1,445 & 95,195 \\
11 & 0,106 & 1,418 & 1,442 & 0,501 & 1,445 & 95,195 \\
12 & 0,106 & 1,418 & 1,442 & 0,501 & 1,445 & 95,195 \\
\hline
\end{tabular}

Fonte: Dados da pesquisa.

Tabela 14 - Decomposição histórica da variância do erro de previsão para a exportação de algodão em pluma do Brasil - Modelo com a produção de algodão

\begin{tabular}{|c|c|c|c|c|c|c|}
\hline \multirow{2}{*}{ Anos } & Desvio-padrão & \multicolumn{5}{|c|}{ Decomposição da variância devida a choques em (\%) } \\
\cline { 3 - 7 } & & PIB & PRODT & EXP & PRODUÇAO & PR INT \\
\hline 1 & 1,110 & 1,724 & 24,273 & 31,108 & 42,469 & 0,426 \\
2 & 1,206 & 4,309 & 23,972 & 28,045 & 36,118 & 7,556 \\
3 & 1,219 & 4,986 & 23,778 & 27,530 & 35,866 & 7,839 \\
4 & 1,220 & 4,987 & 23,757 & 27,505 & 35,920 & 7,831 \\
5 & 1,220 & 4,989 & 23,764 & 27,499 & 35,914 & 7,835 \\
6 & 1,220 & 4,989 & 23,765 & 27,498 & 35,912 & 7,835 \\
7 & 1,220 & 4,989 & 23,765 & 27,498 & 35,912 & 7,835 \\
8 & 1,220 & 4,989 & 23,765 & 27,498 & 35,912 & 7,835 \\
9 & 1,220 & 4,989 & 23,765 & 27,498 & 35,912 & 7,835 \\
10 & 1,220 & 4,989 & 23,765 & 27,498 & 35,912 & 7,835 \\
11 & 1,220 & 4,989 & 23,765 & 27,498 & 35,912 & 7,835 \\
12 & 1,220 & 4,989 & 23,765 & 27,498 & 35,912 & 7,835 \\
\hline
\end{tabular}

Fonte: Dados da pesquisa.

\subsubsection{Análise das funções de impulso resposta}

Nesta subseção serão analisados os impactos de choques de cada variável sobre si mesma e sobre as demais variáveis. Os impactos foram praticamente idênticos para cada variável nos dois modelos, de área e de produção.

Na Figura 7 são apresentados os impactos que cada variável apresenta devido a choques em si mesmas. Todas as linhas estão partindo do valor 1,00 , significando que choque de $10 \%$ causa um impacto inicial de $10 \%$. Nos períodos seguintes, tem-se a tendência dos impactos. Inicialmente, observa-se que choque na renda interna tende a ser maior no segundo período após o choque, tendo ligeira queda e se estabilizando em seguida. Para as demais variáveis, observa-se que o choque de $10 \%$ em cada uma delas não apresenta um impacto acumulado na mesma proporção, mas as variações são expressivas e positivas.

As variáveis produtividade e produção apresentaram impactos semelhantes: choques de $10 \%$ em cada uma dessas variáveis produz um impacto acumulado de $8,9 \%$. Os resultados sugerem, portanto, que aumentos - por exemplo - de produtividade (ou produção) tendem a ser apenas levemente ate- 
nuados, ou seja, há apenas uma pequena contenção da expansão inicial, o que este trabalho associa à possibilidade de exportação inibir possível desestímulo ligado à queda de preço. Evolução semelhante também foi obtida para a área colhida com algodão. Um choque inicial de $10 \%$ na exportação também produz uma resposta acumulada levemente atenuada: uma vez conquistada uma expansão no mercado, ela tende a ser preservada.

Tabela 15 - Decomposição histórica da variância do erro de previsão para a produção de algodão em caroço (herbáceo e arbóreo) no Brasil - Modelo com a produção de algodão

\begin{tabular}{|c|c|c|c|c|c|c|}
\hline \multirow{2}{*}{ Anos } & Desvio-padrão & \multicolumn{5}{|c|}{ Decomposição da variância devida a choques em (\%) } \\
\cline { 3 - 7 } & & PIB & PRODT & EXP & PRODUÇAO & PR INT \\
\hline 1 & 0,156 & 0,000 & 29,801 & 0,000 & 70,199 & 0,000 \\
2 & 0,173 & 0,576 & 28,103 & 0,894 & 58,333 & 12,094 \\
3 & 0,176 & 0,798 & 28,082 & 0,933 & 56,273 & 13,914 \\
4 & 0,176 & 0,802 & 28,064 & 0,987 & 55,974 & 14,173 \\
5 & 0,176 & 0,802 & 28,054 & 1,002 & 55,942 & 14,200 \\
6 & 0,176 & 0,803 & 28,052 & 1,006 & 55,936 & 14,204 \\
7 & 0,176 & 0,803 & 28,051 & 1,006 & 55,935 & 14,204 \\
8 & 0,176 & 0,803 & 28,051 & 1,006 & 55,935 & 14,205 \\
9 & 0,176 & 0,803 & 28,051 & 1,006 & 55,935 & 14,205 \\
10 & 0,176 & 0,803 & 28,051 & 1,006 & 55,935 & 14,205 \\
11 & 0,176 & 0,803 & 28,051 & 1,006 & 55,935 & 14,205 \\
12 & 0,176 & 0,803 & 28,051 & 1,006 & 55,935 & 14,205 \\
\hline
\end{tabular}

Fonte: Dados da pesquisa.

Figura 7 - Função de impulso resposta acumulada do PIB, da produtividade, do preço interno, da exportação, da produção e da área, a impulso em sua própria variável

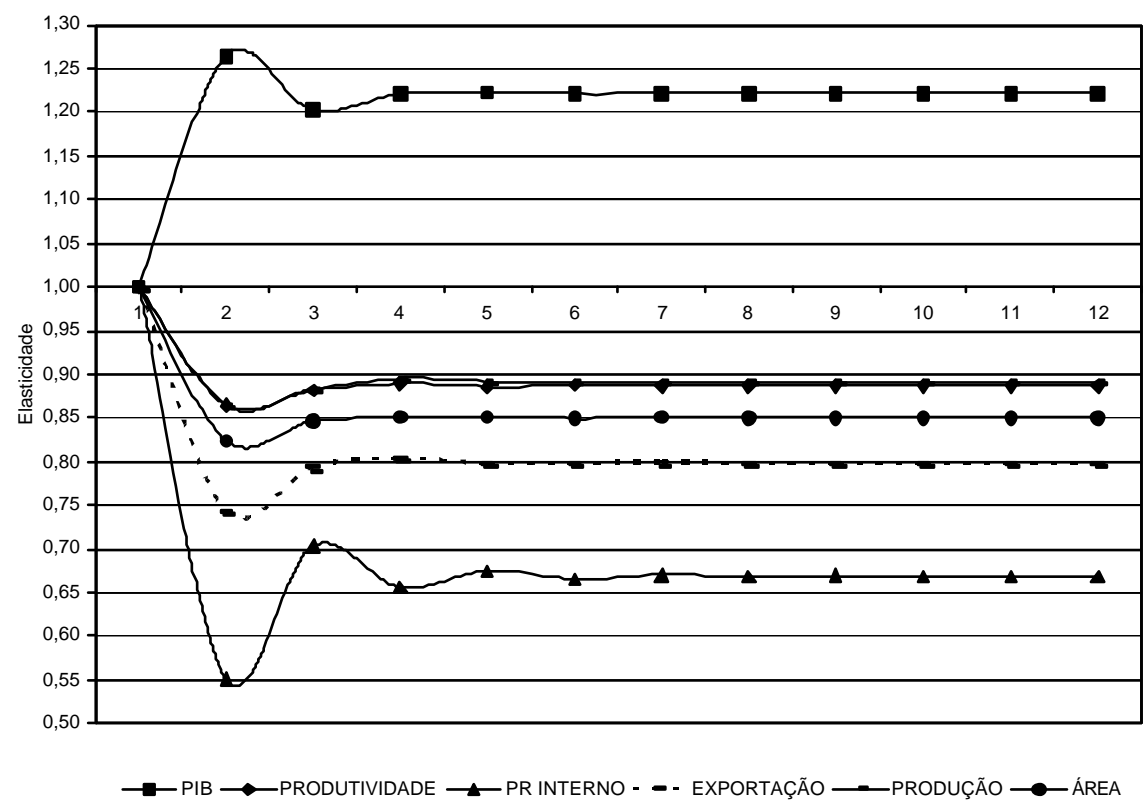

Fonte: Dados da pesquisa. 
Um choque de preço tende a ser seguido por maior oscilação: se o preço se valoriza, há uma tendência de maior produção e queda no consumo levando a moderação da alta inicial. Contudo, no final do período os preços tendem a permanecer maiores que antes do choque.

Em seguida, se analisa a função de impulso resposta da produção, da área e da exportação, devido a choques nas demais variáveis do modelo. Inicia-se a análise interpretando os resultados da função para a área, apresentados na Figura 8. De acordo com a decomposição da variância do erro de previsão, duas variáveis se mostraram importantes em explicar variações da área colhida: produtividade agrícola e preços do algodão. Observa-se que essas duas variáveis causam impactos semelhantes, por serem indicadores de rentabilidade da produção. Choque de $10 \%$ na produtividade (preço) causa impacto de $4,4 \%(4,2 \%)$ sobre a área, no segundo período após o choque. O impacto final acumulado é de $3 \%$ sobre a área.

Pela decomposição da variância do erro de previsão, também foram a produtividade e o preço do algodão que se mostraram importantes em explicar variações da produção. Na Figura 9, nota-se que a produção se mostrou mais influenciada pela produtividade do que pelo preço do algodão. Conforme modelado, a produção responde contemporaneamente a choques de produtividade: $8,5 \%$ para um choque inicial de $10 \%$, com efeito acumulado de $10,06 \%$. Apesar de responder contemporaneamente ao choque, haveria um período de adaptação para que o produtor possa usar a tecnologia de forma eficiente.

A resposta ao choque de preço ocorre com defasagem: para cada choque positivo de $10 \%$ no preço, a produção tende a crescer $6,4 \%$ no período seguinte. No acumulado do período, a resposta ao choque é de 4,4\% (Figura 9). Esse padrão de resposta decorreria do padrão de variação do preço apresentado na Figura 7, onde se verifica que um aumento inicial de preço tende a se moderar com a passagem do tempo, levando a que seu impacto sobre a produção fique também diminuído. As respostas aos choques do PIB e do preço interno foram iguais nos dois modelos considerados neste trabalho (com a área colhida e com a produção): choque positivo no PIB conduz a redução do excedente de produção, com um decréscimo expressivo das exportações de algodão em pluma. No acumulado, observou-se um impacto de $15,4 \%$ para cada choque inicial de $10 \%$ na renda interna.

Choque positivo no preço interno mostrou uma resposta negativa das exportações contemporaneamente, mas que se recuperaram expressivamente nos períodos seguintes. Um aumento de preço (tanto interna como externamente) leva - após ajustes de mercado - a um aumento proporcionalmente maior (quase o dobro) nas exportações. Lembra-se que o excedente exportável cresce em razão do aumento da área plantada e da redução do consumo interno.

Aumentos de área e de produção favorecem a geração de maior excedente do produto, que deverá ser destinado ao mercado externo. Choques positivos de $10 \%$ nestas variáveis causam um aumento de $55,3 \%$ na exportação (Figura 10). Resultados semelhantes e mais expressivos foram obtidos a partir de choques na produtividade: aumento de $10 \%$ na produtividade aumenta em sete vezes a exportação. Os valores relativamente altos das variações das exportações se devem ao volume pequeno das exportações brasileiras de algodão comparadas à produção do país e à baixa participação do Brasil no comércio mundial.

\section{CONSIDERAÇÕES FINAIS}

Neste trabalho argumenta-se que a expansão marcante da produção de algodão, mesmo com os preços em queda desde meados dos anos 1970, decorreu de uma conjugação de fatores de ordem tecnológica (do lado da oferta) e mercadológica (do lado da demanda). A capacidade empresarial e empreendedora dos produtores brasileiros foi essencial para transformar as oportunidades e superar os obstáculos para que a produção de algodão e derivados alcançasse o elevado padrão de produtividade e eficiência dos dias de hoje.

O modesto crescimento da economia brasileira - após o boom dos anos 1970 - foi, em parte, compensado por uma abertura para o comércio exterior a partir do final dos anos 1980. Evidentemente entre 
esses períodos ficou uma lacuna, que veio a ser denominada de "década perdida". Visando a atender a esse mercado, o setor se organiza e se transforma numa "cotonicultura empresarial" - transferindo mesmo em massa para outras regiões onde as limitações e as restrições fundiárias - entre outras - pudessem ser superadas. Ao mesmo tempo, foca-se na busca por tecnologia, condição sine qua non para a necessária competitividade e sobrevivência na economia que se globalizava. A partir dos anos 1990 verifica-se um processo de redefinição institucional. Devido à escassez de recursos estatais a partir dos anos de 1980, o sistema público de pesquisa foi necessariamente encolhido. A iniciativa privada passa a investir em pesquisa, especialmente a partir de 1997, quando foi aprovada a Lei de Proteção de Cultivares - LPC.

Figura 8 - Função de impulso resposta acumulada da área, a impulso no PIB, na produtividade, no preço interno e na exportação

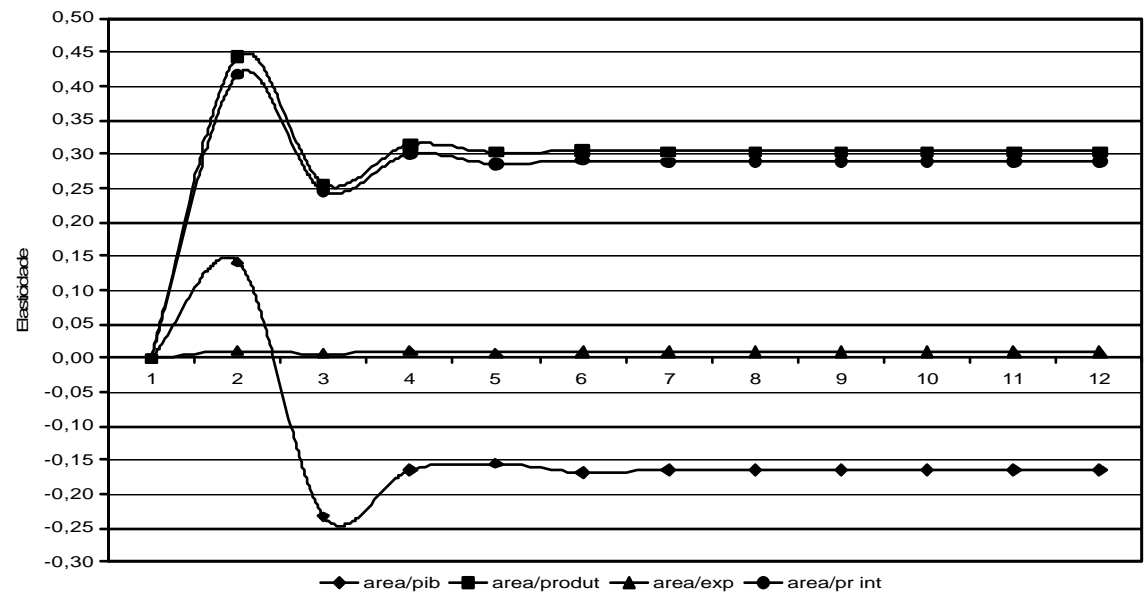

Fonte: Dados da pesquisa.

Essa tecnologia que resulta desse intricado processo leva efetivamente a saltos de produtividade que se viabilizam graças às exportações, que moderavam as quedas de preços que fatalmente ocorreriam caso a expansão da produção ficasse represada no mercado interno. A produtividade agrícola de algodão em caroço que nos 20 anos anteriores a 1985 estagnara-se abaixo de $600 \mathrm{~kg} / \mathrm{ha}$, em 1997 alcança 1.400 $\mathrm{kg} / \mathrm{ha}$, e em 2004 ultrapassa $3.300 \mathrm{~kg} / \mathrm{ha}$.

A pesquisa aqui relatada apontou que a área colhida com algodão tem uma evolução fortemente marcada por um processo auto-regressivo. Aparentemente, definidas as condições gerais econômicas e tecnológicas, a área da cultura passa a seguir um processo de elevação ou redução em direção ao valor desejado que pode levar uma década ou mais. Ela tem sido pouco influenciada por variações marginais nas variáveis econômicas, indicando que uma vez estabelecida numa região, a cultura do algodão tende a seguir uma evolução própria que somente será expressivamente alterada diante de mudanças vultosas em preços e custos, o que ocorreu basicamente em duas ocasiões: meados de 1980 e 1990.

O estudo também apresenta evidências de que perto de $30 \%$ do crescimento da produção de algodão no Brasil se deveu ao comportamento da produtividade da lavoura; esta teve um comportamento exógeno, no sentido de que resultou do uso de tecnologias que foram geradas e utilizadas independentemente das forças econômicas setoriais. Essas tecnologias proviriam, portanto, do esforço das instituições de pesquisa nacionais e estrangeiras, que as disponibilizaram aos produtores, que as adaptaram e adotaram face à expectativa de aumento da rentabilidade da cultura. 
Figura 9 - Função de impulso resposta acumulada da produção, a impulso no PIB, na produtividade, no preço interno e na exportação

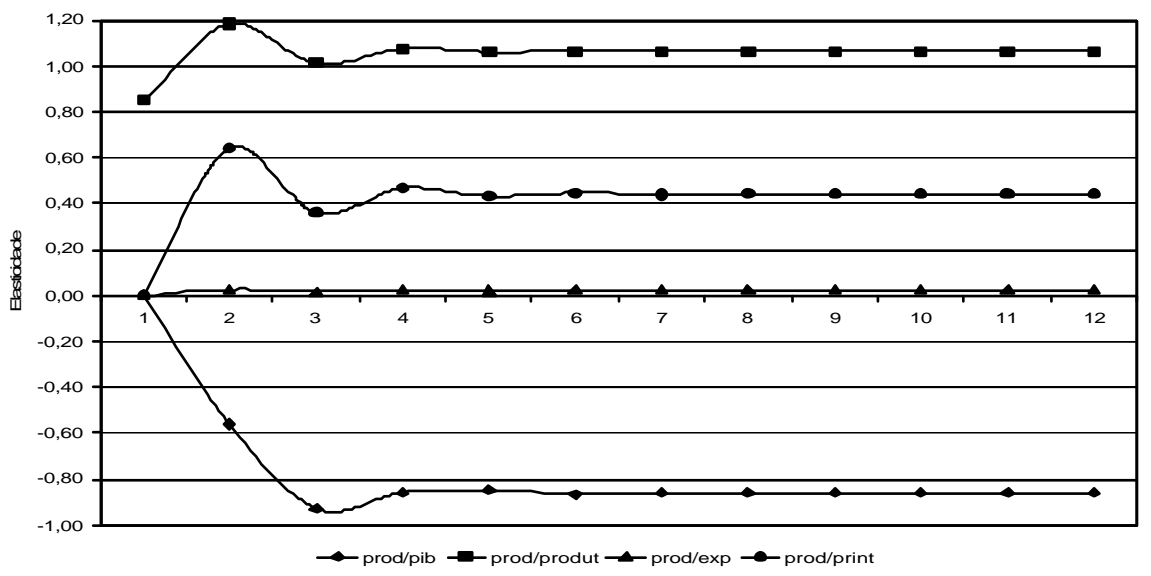

Fonte: Dados da pesquisa.

Figura 10 - Função de impulso resposta acumulada da exportação, a impulso no PIB, na produtividade dos modelos com produção e com a área, no preço interno e na produção e área

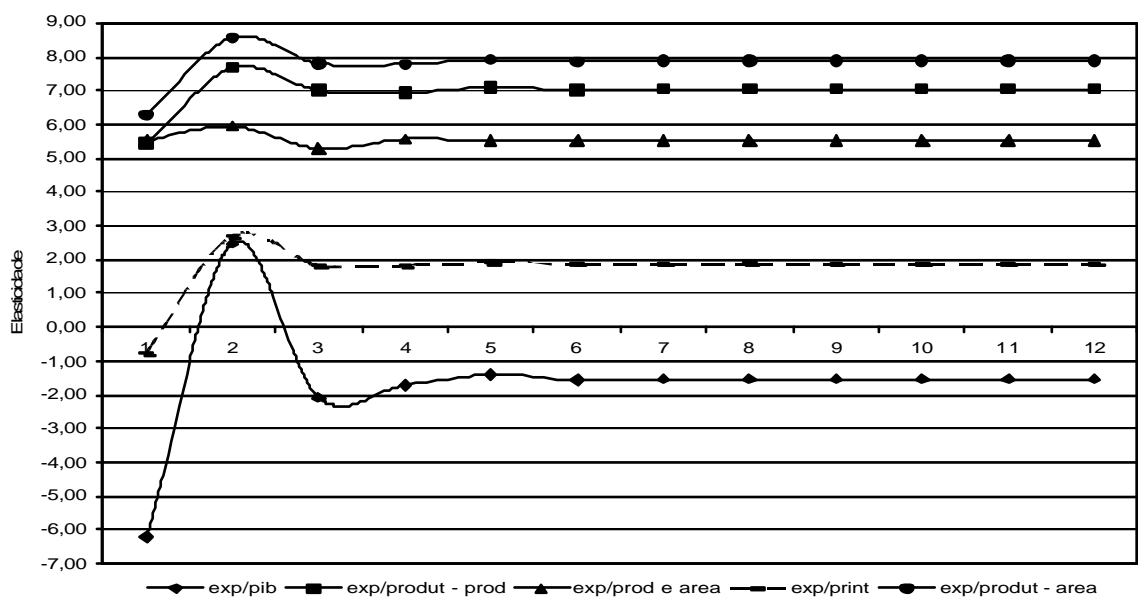

Fonte: Dados da pesquisa. 
Outros $15 \%$ do aumento da produção pode ser atribuído à evolução do preço. Este, por sua vez, tem um comportamento essencialmente exógeno, compatível, assim, com a hipótese de que seja formado basicamente no mercado externo. Como os preços no Brasil e no exterior apresentaram tendência de queda, exceto na década de 1970, acredita-se que somente nesse último período os preços tenham contribuído para a expansão da produção de algodão no Brasil. Desde então seu papel mais importante tem sido o de alocar as disponibilidades entre consumo interno e exportação. Não quer isso dizer que os preços não sejam relevantes para a produção, mas sim que acompanhando os preços externos - e não a evolução da produção nacional -, os preços domésticos têm garantido maior ou menor rentabilidade ao produtor brasileiro ao mesmo tempo em que vai tornando viável o emprego de tecnologias indutoras do aumento da produtividade.

Quase um quarto da evolução da exportação de algodão pode ser atribuído ao comportamento da produtividade. Este tipo de efeito certamente predominou em períodos recentes - de 1985 em diante e, em especial após 1998 -, em que a produtividade apresentou crescimento quase explosivo. Entre trinta e cinco e quarenta porcento se devem a mudanças de produção não associadas diretamente à produtividade e preços. Esse efeito pode ter sido de duas naturezas: (a) até 1985 quando a produtividade estava praticamente estagnada e as oscilações com alto componente aleatório poderiam levar a excedente exportável maior ou menor; (b) após 1995, quando começam a predominar fatores ligados à eficiência produtiva, como economias de escala ou tamanho, com a produção se expandindo marcantemente no Centro-Oeste.

Em suma, pode-se dizer que o desenvolvimento da cotonicultura brasileira deve ser atribuído principalmente a mudanças do lado da oferta, através de avanços tecnológicos e gerenciais que resultaram em maior eficiência e produtividade agrícola. Isto contribuiu para que a cotonicultura brasileira superasse surpreendentemente um período de crise, de baixa produção interna e expressiva necessidade de importações para suprir a demanda interna de pluma, para se tornar um importante produtor e exportador mundial, em um período relativamente curto de tempo.

\section{BIBLIOGRAFIA}

Baer, W. (1996). A Economia Brasileira. Nobel, São Paulo.

Barros, G. S. A. C., Spolador, H. F. S., \& Bacchi, M. R. P. (2006). Supply and demand shocks and the growth of the Brazilian agriculture. In International Association of Agricultural Economists, page 26. IAAE, Broadbeach.

Barros, J. R. M. (1979). Política e desenvolvimento agrícola no Brasil. In Veiga, A., editor, Ensaios Sobre Política Agrícola, pages 9-35. Secretaria da Agricultura, São Paulo.

Barros, J. R. M., Pastore, A. C., \& Rizzieri, J. A. B. (1977). A evolução recente da agricultura brasileira. In Barros, J. R. M. \& Graham, D. H., editors, Estudos sobre a Modernização da Agricultura Brasileria, pages 107-138. IPE, São Paulo.

Bernanke, B. S. (1986). Alternative explanations of the money-income correlation. Carnegie-Rochester Conference Series on Public Policy, 25:49-100.

Blanchard, O. J. \& Quah, D. (1989). The dynamic effects of aggregate demand and supply disturbances. The American Economic Review, 39(4):655-673.

Blanchard, O. J. \& Quah, D. (1993). The dynamic effects of aggregate demand and supply disturbances: Replay. The American Economic Review, 83(3):653-658.

Cochrane, W. W. (1958). Farm Prices: Myth and Reality. University of Minnesota Press, Minneapolis. 
Coelho, A. B. (2002). A cultura do algodão e a questão da integração entre preços internos e externos. Dissertação de mestrado, Faculdade de Economia, Administração e Contabilidade, Universidade de São Paulo, São Paulo.

Coelho, C. N. (2001). 70 anos de política agrícola no Brasil. Revista de Política Agrícola, 10(3):1-59.

Cover, J. P., Enders, W., \& Hueng, C. J. (2002). Using the aggregate demand-aggregate supply model to identify structural demand-side and supply-side shocks: Results using a bivariate VAR. Technical Report 02-08-02, Tuscaloosa: The University of Alabama.

Dickey, D. A. \& Fuller, W. A. (1979). Distribution of the estimator for auto-regressive time series with a unit root. Journal of the American Statistical Association, 74(366):427-431.

Dickey, D. A. \& Fuller, W. A. (1981). Likelihood ratio statistics for autoregressive time series with a unit root. Econometrica, 49(4):1057-1072.

Enders, W. (1995). Applied Econometric Time Series. John Wiley \& Sons, New York.

Engle, R. F. \& Granger, C. W. J. (1987). Co-integração and error corretion: Representation, estimation, and testing. Econometrica, 55(2):251-276.

Fao (2006). Agriculture: Crops \& livestock primary \& processed. Disponível em: http:// faostat.fao.org. Acesso em: 19/jan/2006.

Gasques, J. G., Bastos, E. T., Bacchi, M. R. P., \& Conceição, J. C. P. R. (2003). Condicionantes da produtividade da agropecuária brasileira. Instituto de Pesquisa Econômica Aplicada, 34 p. Projeto BRA 97/013, Pesquisa 31 A/1P, Brasília.

Gopinath, M. \& Roe, T. L. (1997). Sources of sectorial growth in an economy wide context: The case of U.S. agriculture. Journal of Productivity Analysis, 8:293-310.

Hamilton, J. D. (1994). Time Series Analysis. Princenton University Press, Princenton.

Harvey, A. (1990). The Econometric Analysis of Time Series. MIT Press, Cambridge.

Instituto Brasileiro de Geografia e Estatística - IBGE (2005). SIDRA: Agricultura. Disponível em: http://www.sidra.ibge.gov.br. Acesso em: 28/jul/2005.

Instituto de Pesquisa Econômica Aplicada - IPEA (2005). IPEADATA. Disponível em: http://www.ipeadata.gov.br/ipeaweb.dll/ipeadata?335353109. Acesso em: $19 / \mathrm{set} / 2005$.

Instituto de Pesquisa Econômica Aplicada - IPEA (2006). IPEADATA. Disponível em: http://www.ipeadata.gov.br/ipeaweb.dll/ipeadata?692208765. Acesso em: 19/jan/2006.

Johansen, S. (1988). Statistical analysis of cointegration vectors. Journal of Economic Dynamics and Control, 12:231-254.

Johansen, S. \& Juselius, K. (1990). Maximum likelihood estimation and inference on cointegration with aplications to the demand for money. Oxford Bulletin of Economics and Statistics, 52:169-219.

Keating, J. W. \& Nye, J. V. (1998). Permanent and transitory shocks in real output: Estimates from nineteenth-century and postwar economies. Journal of Money, Credit and Banking, 30(2):231-251. 
King, R. G., Plosser, C. I., Stock, J. H., \& Watson, M. W. (1991). Stochastic trends and economic fluctuations. The American Economic Review, 81(4):819-840.

Ledena, C. E. \& Hertel, T. W. (2006). Effects of productivity growth in primary agriculture on processed food exports and the food processing sector: An historical analysis. Disponível em: http://www.ifama.org/conferences/2005Conference/ Papers\&Discussions/1117_Paper_Final.pdf. Acesso em: 2/abr/2006.

Lima, E. C. R., Migon, H. S., \& Lopes, H. F. (1992). Efeitos dinâmicos dos choques de oferta e demanda agregada sobre o nível de atividade econômica do Brasil. Technical Report 267, IPEA.

Lima, E. C. R., Migon, H. S., \& Lopes, H. F. (1993). Efeitos dinâmicos dos choques de oferta e demanda agregada sobre o nível de atividade econômica do Brasil. Revista Brasileira de Economia, 47(2):177-204.

Lippi, M. \& Reichlin, L. (1993). The dynamic effects of aggregate demand and supply disturbances: Comment. The American Economic Review, 83(3):644-652.

Lopes, M. R. (1992). Os efeitos das coalizões nas políticas agrícolas e o comércio exterior dos produtos agrícolas no Brasil. Agricultura em São Paulo, 39(2):23-41.

Lütkepohl, H. (1991). Introduction to Multiple Time Series Analysis. Springer-Verlag, Berlin.

Martin, W. \& Mitra, D. (1999). Productivity growth and convergence in agriculture and manufacturing. Technical Report 2171, Washington: World Bank. Disponível em: http: / /www-wds.worldbank.org/servlet/WDSContentServer/WDSP / IB/ 1999/09/25/000094946_99090805303688/Rendered/PDF/multi_page.pdf. Acesso em: 2/abr/2006.

Negri Neto, A. (2001). Análise dos estudos econométricos sobre a oferta agrícola no IEA. Análise de conjuntura. São Paulo, Outubro de 2001. Disponível em: http: / / www . iea.sp.gov . br / OUT / verTexto.php?codTexto=375. Acesso em 26/set/2008.

Oehmke, J. F. \& Schimmelpfennig, D. E. (2004). Quantifuing structural change in U.S. agriculture: The case of research and productivity. Journal of Productivity Analysis, 21(3):297-315.

Osterwald-Lenum, M. (1992). A note with quantiles of the asymptotic distribution of the maximum likelihood cointegration rank test statistics. Oxford Bulletin of Economics and Statistics, 53(3):461472 .

Paiva, R. M. (1968). O mecanismo de autocontrole no processo de expansão da melhoria técnica da agricultura. Revista Brasileira de Economia, 24(3):15-17.

Ruttan, V. W. (2002). Productivity growth agriculture: Sources and constraints. Journal of Economic Perspective, 16(4):161-184.

Shane, M., Roe, T., \& Gopinath, M. (1998). U.S. agriculture growth and productivity. Technical Report 758, Washington: U.S. Department of Agriculture, Economic Research Service. Disponível em: http: / /www.ers.usda.gov/Publications/aer758. Acesso em: 10/mar/2006.

Szmrecsányi, T. (1990). Pequena História Da Agricultura No Brasil. Editora Contexto, São Paulo.

Teixeira, J. C. (2005). Modernização da agricultura no Brasil: Impactos econômicos, sociais e ambientais. Revista Eletrônica da Associação dos Geógrafos Brasileiros, 2(2):21-42. 